\title{
PEMODELAN NOWCASTING TINGKAT PENGANGGURAN TERBUKA MENGGUNAKAN DATA GOOGLE TRENDS DENGAN METODE ANTLION OPTIMIZATION-SUPPORT VECTOR REGRESSION
}

\author{
Studi Kasus di Provinsi Jawa Barat pada 2005-2019
}

(Nowcasting Unemployment Rate Using Google Trends Data and Antlion OptimizationSupport Vector Regression Method)

\author{
IImi Aulia Akbar'1, Robert Kurniawan² \\ Politeknik Statistika STIS ${ }^{1}$ \\ Politeknik Statistika STIS ${ }^{2}$ \\ Jl. Otto Iskandar Dinata No. 64C Jakarta 13330 \\ E-mail: 16.9193@stis.ac.id
}

\begin{abstract}
ABSTRAK
Tingkat Pengangguran Terbuka (TPT) adalah salah satu indikator strategis nasional yang didapatkan oleh BPS melalui Survei Angkatan Kerja Nasional (SAKERNAS) yang dilaksanakan dua kali dalam satu tahun, yaitu pada Februari dan Agustus. Terdapat lag waktu tiga bulan sejak data dikumpulkan hingga data dipublikasikan dan dapat diatasi menggunakan nowcasting dengan memanfaatkan data Google Trends. Data indeks pencarian dari kueri yang berkaitan dengan proses pencarian kerja kemudian diseleksi menggunakan koefisien korelasi Pearson dan LASSO hingga diperoleh kueri pencarian yang relevan dengan nilai TPT. Pemodelan nowcasting dilakukan menggunakan Support Vector Regression dengan parameter yang dioptimisasi menggunakan Ant-Lion Optimization. Dari penelitian ini diperoleh tiga kueri pencarian yang relevan dan dapat digunakan untuk nowcasting TPT Jawa Barat yaitu "lowongan kerja", "lowongan pekerjaan", dan "job". Hasil dari pemodelan juga menunjukkan MAE, MAPE, dan RMSE yang baik.
\end{abstract}

Kata kunci: TPT, nowcasting, Google Trends, SVR, ALO

\section{ABSTRACT}

The Unemployment Rate is one of the national strategic indicators obtained by BPS through the National Labor Force Survey (SAKERNAS) which is carried out twice a year in February and August. There is a lag of three months from the time data is collected until the data is published which can be overcome using nowcasting by utilizing Google Trends data. Search index data from queries related to the job search process are then selected using Pearson correlation coefficients and LASSO to obtain a search query that is relevant to the unemployment rate. The nowcasting models use Support Vector Regression with parameters optimized using Ant-Lion Optimization. From this research, three search queries that are relevant and can be used for nowcasting unemployment rate in West Java are obtained, which are "lowongan kerja", "lowongan pekerjaan", and "job". The results from modeling also show good MAE, MAPE, and RMSE.

Keywords: unemployment rate, nowcasting, Google Trends, SVR, ALO

\section{PENDAHULUAN}

Tingkat Pengangguran Terbuka (TPT) adalah persentase jumlah pengangguran terhadap jumlah angkatan kerja yang diperlukan untuk membantu pemerintah dalam memperbaiki masalah ketenagakerjaan di Indonesia, khususnya masalah pengangguran. Nilai TPT didapatkan oleh BPS melalui Survei Angkatan Kerja Nasional (SAKERNAS) yang dilaksanakan dua kali dalam satu tahun, yaitu pada Februari dan Agustus (BPS, 2019). Pengumpulan data ketenagakerjaan melalui SAKERNAS melalui proses yang panjang, sehingga hasil survei SAKERNAS Februari baru dipublikasikan pada Mei (Virati et al., 2019). Hal ini berarti terdapat lag waktu tiga bulan sejak data dikumpulkan hingga data dipublikasikan.

Permasalahan lag waktu ini dapat diatasi dengan pemanfaatan Big Data. Kecepatan Big Data dalam menghasilkan data, serta kecepatan perubahan, penerimaan, proses, dan pemahaman data dapat digunakan untuk meningkatkan timeliness dan frekuensi dari publikasi data untuk memenuhi 
kebutuhan data statistik (Tam \& Clarke, 2015). Salah satu potensi Big Data yang dapat dimanfaatkan adalah sifatnya yang real-time dan dapat digunakan untuk memprediksi keadaan saat ini atau nowcasting.

Google Trends menjadi salah satu sumber data yang dapat digunakan untuk nowcasting. Penelitian yang sudah ada mengenai penggunaan Google Trends umumnya menggunakan metode analisis runtun waktu secara statistik seperti ARIMA (Askitas et al., 2009; Fondeur \& Karamé, 2013; Naccarato et al., 2017). Namun, terdapat bukti bahwa dalam beberapa kasus, nonlinearitas dapat menghasilkan model prediksi yang lebih baik (Deng et al., 2005).

Perkembangan teknologi menjadikan analisis runtun waktu kini tidak hanya dilakukan menggunakan menggunakan statistika klasik, tetapi juga machine learning. Salah satu metode machine learning yang umum digunakan pada analisis runtun waktu adalah Support Vector Regression. Support Vector Regression adalah teknik regresi berdasarkan konsep support vector. (Richardson et al., 2018). Akan tetapi, meskipun SVR menyediakan solusi yang efektif untuk prediksi data runtun waktu, SVR memiliki kecenderungan terjebak di local optimum (Torres, 2018). Local optimum dapat diatasi algoritma metaheuristic, yaitu algoritma dengan operator stokastik yang memiliki sifat acak sebagai karakter utamanya. Salah satu algoritma metaheuristic adalah Ant Lion Optimization (ALO), yaitu algoritma heuristik biologis yang bekerja dengan meniru cara undur-undur berburu semut (Mirjalili, 2015).

Jawa Barat merupakan provinsi dengan penetrasi internet yang tergolong tinggi. Berdasarkan data BPS (2017), Jawa Barat memiliki persentase penduduk berusia lebih dari 5 tahun yang pernah mengakses internet terbanyak keempat di Indonesia sebesar 37,02 persen. Oleh karena itu, dapat dilakukan nowcasting TPT Jawa Barat untuk mengatasi lag waktu rilis TPT menggunakan Google Trends. Penelitian ini bertujuan untuk mengidentifikasi kueri-kueri pencarian yang relevan dengan TPT Jawa Barat dan membangun model nowcasting TPT di Jawa Barat menggunakan data Google Trends dengan metode pemodelan SVR-ALO.

Penelitian mengenai penggunaan data indeks pencarian untuk peramalan angka pengangguran telah dilakukan sebelumnya. Salah satu penelitian yang telah dilakukan adalah penelitian Askitas et al. (2009) mengenai potensi penggunaan data Google Insight dalam peramalan angka pengangguran bulanan di Jerman. Hasil dari penelitian ini menunjukkan adanya korelasi yang kuat antara data Google Insight dengan angka pengangguran bulanan.

Penelitian lainnya yang telah dilakukan adalah penelitian mengenai penggunaan data Google Trends untuk memprediksi jumlah pengangguran usia 15 sampai 24 tahun di Prancis (Askitas et al., 2009). Hasil dari penelitian ini menunjukkan bahwa penggunaan data Google Trends dapat menghasilkan prediksi yang lebih baik dibandingkan model lain yang tidak menggunakan data penelusuran internet.

Penggunaan data indeks pencarian untuk memprediksi angka pengangguran juga telah dilakukan oleh Barreira et al. (2013) mengenai nowcasting angka pengangguran dan penjualan mobil di Eropa Barat Daya menggunakan data Google Trends. Hasil dari penelitian ini juga menunjukkan bahwa ketika variabel Google Trends berbeda secara signifikan dari in-sample secara umum dapat meningkatkan kemampuan prediksi pada out-sample.

Penelitian selanjutnya menggunakan data Google Trends untuk memprediksi pengangguran muda di Italia (Naccarato et al., 2017). Hasil dari penelitian ini menunjukkan bahwa penggunaan informasi tambahan dari Google Trends memiliki rata-rata forecast error yang lebih kecil.

Penelitian lainnya adalah pengembangan sistem analisis Big Data yang membandingkan angka TPT dengan indeks volume pencarian kata kunci 'kerja', 'lowongan kerja', dan 'loker' (Virati et al., 2019). Akan tetapi, penelitian ini tidak menjelaskan mengenai dasar pemilihan kata kunci tersebut sebagai variabel pembanding. Penelitian ini juga hanya membandingkan indeks volume pencarian dengan TPT tanpa melakukan pemodelan dan prediksi TPT.

\section{METODE}

\section{TPT}


Tingkat Pengangguran Terbuka (TPT) adalah persentase jumlah pengangguran terhadap jumlah angkatan kerja. TPT merupakan salah satu indikator strategis nasional yang diperlukan untuk membantu pengambil keputusan dalam mengambil kebijakan untuk mengatasi dan memperbaiki masalah ketenagakerjaan di Indonesia, khususnya masalah pengangguran. TPT yang tinggi menunjukkan bahwa terdapat banyak angkatan kerja yang tidak terserap pada pasar kerja (BPS, 2019).

\section{Google Trends}

Google Trends merupakan layanan dari Google yang menyediakan akses pada sampel unbiased dari penelusuran yang dilakukan menggunakan mesin pencari Google. Sampel data tersebut bersifat anonim, terkategori, dan agregat. Data ini dapat digunakan untuk melihat ketertarikan terhadap suatu topik dari seluruh dunia hingga level geografis yang lebih kecil seperti provinsi atau kota (Google Support, 2020). Google Support (2020) menjelaskan terdapat dua jenis data Google Trends yang dapat diakses, yaitu:

1. Data real-time, yaitu sampel acak dari data yang mencakup penelusuran selama tujuh hari terakhir sebelum data tren dibentuk;

2. Data non real-time, yaitu sampel dari data yang mencakup penelusuran dari tahun 2004 hingga 36 jam sebelum data tren dibentuk.

Google Trends melakukan normalisasi pada data untuk memudahkan perbandingan antar istilah penelusuran. Setiap istilah atau kueri penelusuran dibagi dengan volume total kueri penelusuran dari wilayah geografis dan rentang waktu tertentu untuk membandingkan popularitas relatif. Hasil yang didapatkan kemudian diskalakan dengan rentang 0 sampai 100 berdasarkan proporsi topik tersebut terhadap penelusuran seluruh topik (Google Support, 2020).

\section{SVR}

Support Vector Regression adalah metode supervised learning yang digunakan untuk menyelesaikan masalah estimasi fungsi multidimensional. Pada mulanya SVR dirancang untuk menyelesaikan masalah pattern recognition, dimana untuk menemukan decision rule dengan kemampuan generalisasi yang baik dipilih subset kecil dari data training yang disebur Support Vectors (SV). Pemisahan SV yang optimal dianggap sama dengan pemisahan data keseluruhan yang paling optimal (Deng et al., 2005).

Diberikan training data $\left\{\left(x_{1}, y_{1}\right), \ldots,\left(x_{1}, y_{1}\right)\right\} \subset X \times \mathbb{R}$, dimana $\mathrm{X}$ merupakan dimensi input space. Tujuan fungsi ini adalah untuk mendapatkan fungsi $f(x)$ yang memiliki deviasi $(\varepsilon)$ setipis mungkin. Dengan kata lain, error diabaikan selama masih berada di bawah nilai $\varepsilon$ tetapi tidak boleh melebihi nilai tersebut. pada kasus fungsi linear, fungsi $f$ didefinisikan Smola (2004) sebagai:

$$
f(x)=\langle w, x\rangle+b \quad \text { dengan } w \in X, b \in R
$$

dimana (1) merupakan dot product pada X. Fungsi yang setipis mungkin dari persamaan (1) diperoleh melalui nilai dari $\|w\|^{2}$ yang diminimalisasi. Secara formal, masalah ini dituliskan Smola (2004) sebagai:

$\begin{aligned} & \text { minimalkan } \frac{1}{2}\|w\|^{2} \\ & \text { untuk }\left\{\begin{array}{l}y_{i}-\left\langle w, x_{i}\right\rangle-b \leq \varepsilon \\ \left\langle w, x_{i}\right\rangle+b-y_{i} \leq \varepsilon\end{array}\right.\end{aligned}$

asumsi pada persamaan di atas adalah bahwa terdapat fungsi $f$ sedemikian rupa yang mengaproksimasi semua pasangan $\left(x_{i}, y_{i}\right)$ dengan presisi $\varepsilon$. Terkadang error diizinkan sehingga digunakan slack variables untuk mengatasi kendala yang tidak dapat dilaksanakan pada persamaan (2), sehingga Smola (2004) mengubah persamaan tersebut menjadi: 


$$
\begin{gathered}
\frac{1}{2}\|w\|^{2}+C \sum_{i=1}\left(\xi_{i}+\xi_{i}^{*}\right) \\
\left\{\begin{array}{cc}
y_{i}-\left\langle w, x_{i}\right\rangle-b & \leq \varepsilon+\xi_{i} \\
\left\langle w, x_{i}\right\rangle+b-y_{i} & \leq \varepsilon+\xi_{i}^{*} \\
\xi_{i}, \xi_{i}^{*} & \geq 0
\end{array}\right.
\end{gathered}
$$

konstanta $\mathrm{C}>0$ menentukan trade-off antara ketipisan dari $f$ dan jumlah dimana deviasi yang bernilai lebih besar dari $\varepsilon$ ditoleransi. Hal ini kemudian berkaitan dengan loss function $|\xi|_{\varepsilon}$ yang dideskripsikan Smola (2004) sebagai:

$$
|\xi|_{\varepsilon}:=\left\{\begin{array}{cc}
0 & j i k a|\xi|<\varepsilon \\
|\xi|-\varepsilon & \text { untuk lainnya }
\end{array}\right.
$$

\section{ALO}

Ant Lion Optimization (ALO) merupakan metode optimisasi yang meniru perilaku undurundur dalam berburu semut di alam (Mirjalili, 2015). Metode optimisasi ini merupakan salah satu metode optimisasi stokastik (metaheuristic), yaitu sekumpulan algoritma dengan operator stokastik termasuk algoritma evolusioner (Back, 1996). Algoritma stokastik memiliki karakteristik khas berupa keacakan. Hal ini berarti algoritma-algoritma ini menggunakan operator acak ketika mencari global optima di ruang pencarian (Hoos \& Stützle, 2004).

Algoritma ALO meniru interaksi antara undur-undur dan semut di dalam jebakan. Untuk memodelkan interaksi tersebut, semut diharuskan untuk bergerak di dalam ruang pencarian dan undur-undur diperbolehkan untuk memburu semut dan menjadi lebih fit dengan menggunakan jebakan. Semut di alam bergerak secara stokastik ketika mencari makanan, sehingga model random walk dipilih oleh Mirjalili (2015) untuk memodelkan gerak semut sebagai berikut:

$$
X(t)=\left[0, \operatorname{cumsum}\left(2 r\left(t_{1}\right)-1\right), \operatorname{cumsum}\left(2 r\left(t_{2}\right)-1, \ldots, \operatorname{cumsum}\left(2 r\left(t_{n}\right)-1\right)\right]\right.
$$

dimana:

cumsum = jumlah kumulatif

$n=$ jumlah iterasi maksimal

$t=$ menunjukkan langkah dari iterasi random walk

$r(t)=$ fungsi stokastik

$r(t)$ merupakan fungsi stokastik yang didefinisikan oleh Mirjalili (2015) sebagai berikut:

$$
r(t)= \begin{cases}1 & \text { if rand }>0.5 \\ 0 & \text { if } \text { rand } \leq 0.5\end{cases}
$$

dimana:

$t=$ iterasi random walk

rand $=$ angka acak yang dibangkitkan dari distribusi uniform dalam rentang $[0,1]$

Random walk dari semut dilakukan berdasarkan rumus (6). Semut memperbarui posisinya dengan random walk pada setiap tahap optimisasi. Akan tetapi, rumus (6) tidak dapat langsung digunakan untuk memperbarui posisi semut karena setiap ruang pencarian memiliki cakupan. Untuk memastikan bahwa semut bergerak dalam rentang ruang pencarian, Mirjalili (2015) melakukan standardisasi posisi semut dengan rumus berikut:

$$
X_{i}^{t}=\frac{\left(X_{i}^{t}-a_{i}\right) \times\left(d_{i}-c_{i}^{t}\right)}{\left(d_{i}^{t}-a_{i}\right)}+c_{i}
$$

dimana: 
$a_{j}=$ nilai minimum dari random walk variabel ke- $j$

$b_{j}=$ nilai maksimum dari random walk variabel ke- $j$

$c_{j}^{t}=$ nilai minimum dari variabel ke- $j$ pada iterasi ke- $t$

$d_{j}^{t}=$ nilai maksimum dari variabel ke- $j$ pada iterasi ke- $t$

Random walk dari semut dipengaruhi oleh jebakan undur-undur dan dimodelkan oleh Mirjalili (2015) secara matematis menggunakan persamaan berikut:

$$
\begin{aligned}
& c_{i}^{t}=\text { Antlion }_{j}^{t}+c^{t} \\
& d_{i}^{t}=\text { Antlion }_{j}^{t}+d^{t}
\end{aligned}
$$

dimana

Antlion $_{j}^{t}=$ posisi undur-undur ke- $j$ pada iterasi ke- $t$.

Roulette wheel digunakan untuk memodelkan kemampuan berburu dari undur-undur. Semut diasumsikan terjebak di hanya satu undur-undur terpilih. Algoritma ALO menggunakan operator roulette wheel untuk memilih undur-undur berdasarkan fitness saat optimisasi. Mekanisme ini memberikan peluang lebih besar kepada undur-undur yang lebih fit untuk menangkap semut (Mirjalili, 2015).

Ketika semut terjatuh ke dalam jebakan, undur-undur melempar pasir ke bagian sisi jebakan setelah menyadari bahwa seekor semut berada di jebakan. Hal ini menyebabkan semut yang mencoba melarikan diri tergelincir ke dalam jebakan. Untuk memodelkan proses ini secara matematis, Mirjalili (2015) menggunakan persamaan:

$$
\begin{aligned}
& c^{t}=\frac{c^{t}}{I} \\
& d^{t}=\frac{d^{t}}{I}
\end{aligned}
$$

dimana

$I=$ rasio

$t=$ iterasi saat ini

$T=$ jumlah iterasi maksimum

$w=$ konstanta di antara $t$ dan $T$

Setelah menangkap mangsa, fitness dan posisi baru dari semut dievaluasi. Jika semut lebih fit dibandingkan undur-undur, posisi undur-undur akan diperbarui dengan formula yang didefinisikan Mirjalili (2015) sebagai berikut:

$$
\text { Antlion }_{j}^{t}=\text { Ant }_{i}^{t} \quad \text { if } f\left(\text { Ant }_{i}^{t}\right)>f\left(\text { Antlion }_{j}^{t}\right)
$$

dimana

$A n t_{j}^{t}=$ posisi ke- $i$ dari semut pada iterasi ke- $t$.

Random walk dari semut dipengaruhi oleh roulette whee/ dan undur-undur sehingga posisi dari semur diperbarui berdasarkan rata-rata dari roulette whee/ dan pergerakan undur-undur elite, dengan persamaan yang didefinisikan oleh Mirjalili (2015) sebagai berikut:

$$
A n t_{i}^{t}=\frac{R_{A}^{t}+R_{E}^{t}}{2}
$$

dimana

$R_{A}^{t}=$ random walk di sekitar undur-undur terpilih pada iterasi ke- $t$

$R_{E}^{t}=$ random walk di sekitar undur-undur elite pada iterasi ke- $t$

\section{Metode Pengumpulan Data}

Terdapat dua jenis data yang digunakan pada penelitian ini, yaitu data TPT sebagai variabel target peramalan (variabel Y) dan data indeks pencarian Google sebagai variabel nowcast 
(variabel X). Data TPT diperoleh dari BPS, sedangkan data indeks pencarian Google diperoleh dari aplikasi web Google Trends.

Data indeks pencarian Google terdapat pada aplikasi web Google Trends. Data indeks pencarian dari kata kunci yang relevan diunduh menggunakan bahasa pemrograman melalui aplikasi RStudio dengan package "gtrendsR". Data indeks pencarian yang didapatkan sudah terstruktur dan tidak perlu dilakukan strukturisasi data.

Kata kunci relevan yang digunakan pada data indeks pencarian diperoleh melalui survei yang dilakukan oleh peneliti. Survei dilakukan pada 18 November 2018 hingga 25 November 2018. Kuesioner untuk survei disebarkan secara online, dengan syarat responden berusia lebih dari 15 tahun. Dari survei tersebut, diperoleh 120 responden dengan 50 responden tidak bekerja saat periode survei dilaksanakan. Terdapat 12 kueri pencarian dasar yang diperoleh melalui survei dan 12 situs pencarian kerja yang digunakan.

Data indeks pencarian diperoleh dari aplikasi web Google Trends menggunakan bahasa pemrograman R melalui aplikasi RStudio dengan package "gtrendsR". Kueri yang digunakan dalam mendapatkan data indeks pencarian diseleksi sehingga hanya kueri yang relevan terhadap peramalan TPT yang digunakan.

Tahap-tahap pengumpulan data Google Trends yang dilakukan dalam penelitian ini adalah sebagai berikut.

1. Menentukan daftar kueri pencarian dasar (seed queries), yaitu kueri pencarian awal yang dianggap relevan dengan proses pencarian kerja dan kegiatan lain yang dilakukan oleh pengangguran.

2. Mengunduh kata kunci yang berkaitan (related queries) untuk menghasilkan lebih banyak kueri sehingga menambah daftar kueri yang dapat digunakan sebagai variabel nowcast.

3. Mengeliminasi kueri duplikat

4. Mengunduh dataset data indeks pencarian yang disesuaikan dengan lokasi penelitian, yaitu Jawa Barat.

5. Feature selection untuk menyeleksi kueri agar kueri pencarian yang digunakan hanya kueri pencarian yang relevan pada model. Pada penelitian ini, metode feature selection yang digunakan adalah filter method dan embedded method.

Pada filter method, kueri pencarian pada daftar kueri diseleksi dengan suatu ukuran proksi. Ukuran proksi yang d igunakan adalah koefisien korelasi Pearson. Kueri pencarian yang dipilih merupakan kueri pencarian yang memiliki koefisien korelasi lebih dari 0.7 dengan TPT.

Pada embedded method, dilakukan seleksi terhadap daftar kueri dengan metode LASSO. Tahapan yang dilakukan pada feature selection dengan embedded method ini antara lain:
a. Menyiapkan dataset
b. Menentukan nilai $\lambda$
c. Melakukan seleksi variabel $\mathrm{X}$

\section{Metode Analisis}

Pemodelan pada penelitian ini dilakukan menggunakan metode SVR yang dioptimisasi oleh ALO. Optimisasi dilakukan pada cost, epsilon, dan gamma untuk menemukan nilai yang paling sesuai sehingga menghasilkan model dengan MAPE terendah. Tahap-tahap yang dilakukan untuk menganalisis data antara lain:

1. Penentuan variabel input

Terdapat dua jenis variabel input yang digunakan, yaitu data indeks pencarian sebagai variabel nowcast (variabel X) dan TPT sebagai variabel target peramalan (variabel $\mathrm{Y}$ ). Variabel nowcast yang digunakan merupakan kata kunci yang dipilih melalui feature selection, sedangkan variabel target peramalan yang digunakan adalah TPT yang telah distandardisasi.

2. Penentuan data training dan testing

Pembagian data training dan testing yang digunakan merujuk pada penelitian Barreira (2013) yang melakukan peramalan terhadap angka pengangguran dengan membagi data 
menjadi data training dan testing menjadi tiga pembagian berbeda yaitu 70 persen untuk data training dan 30 persen untuk data testing, 80 persen untuk data training dan 20 persen unutk data testing, dan 90 persen untuk data training dan 10 persen unutk data testing kemudian membandingkan hasilnya.

3. Training data

Training terhadap data dilakukan menggunakan metode SVR yang dioptimisasi menggunakan ALO. cost, epsilon, dan gamma untuk menemukan nilai yang paling sesuai sehingga menghasilkan model dengan MAPE terendah. Tahapan training data yang dilakukan antara lain:

a. Standardisasi data

b. Membagi data menjadi training dan testing set

Data dibagi menjadi training dan testing set. Data yang digunakan sebagai training set pada tiap-tiap data split adalah Februari 2005 sampai Agustus 2014, Februari 2005 sampai Februari 2016, dan Februari 2005 sampai Agustus 2017.

c. Fungsi optimisasi SVR

Fungsi optimisasi ini merupakan fungsi yang meminimumkan MAPE dari model SVR yang digunakan. Pada penelitian ini, digunakan dua model SVR dengan kernel berbeda yaitu radial dan sigmoid sehingga terdapat tiga fungsi optimisasi yang berbeda untuk tiap-tiap kernel.

d. Inisialisasi cakupan nilai cost, gamma, dan epsilon untuk digunakan dalam fungsi optimisasi. Cost memliki cakupan antara $2^{0}$ sampai $2^{10}$, gamma memiliki cakupan $2^{-5}$ sampai $2^{5}$, dan epsilon memiliki cakupan $2^{-10}$ sampai $2^{0}$.

e. ALO

Optimisasi menggunakan metode ALO dilakukan untuk menemukan nilai cost, gamma, dan epsilon yang meminimalkan nilai MAPE. Tahapan dari metode optimisasi ini antara lain:

1. Untuk meniru proses berburu dari undur-undur, algoritma ALO memilih undurundur dengan roulette whee/ berdasarkan nilai fitness saat optimisasi.

2. Semut melakukan random walk pada ruang pencarian.

3. Semut memasuki jebakan yang dibuat oleh undur-undur sehingga memengaruhi proses random walk semut.

4. Semut tergelincir ke tengah jebakan, kemudian undur-undur melemparkan pasir ke bagian tengah jebakan.

5. Setelah undur-undur menangkap mangsa, fitness dari posisi baru semut dievaluasi. Jika semut lebih fit dibandingkan undur-undur, posisi undur-undur akan diperbarui.

f. Training SVR menggunakan cost, gamma, dan epsilon yang didapatkan dari hasil optimisasi

4. Evaluasi

Evaluasi terhadap model yang dihasilkan dilakukan menggunakan tiga metrik evaluasi yaitu MAE, RMSE, dan MAPE.

\section{HASIL DAN PEMBAHASAN}

\section{Kueri Pencarian Dasar}

Kueri pencarian dasar merupakan kueri pencarian awal yang dianggap relevan dalam proses pencarian kerja dan kegiatan seseorang sebagai pengangguran, sehingga dapat digunakan sebagai variabel tambahan untuk digunakan dalam prediksi TPT dan diperoleh melalui survei. Dari survei tersebut, diperoleh 12 kueri dan 12 situs pencarian kerja yang biasa digunakan oleh pengangguran.

\section{Kueri Pencarian Terkait}

Daftar kueri pencarian dasar yang diperoleh dari survei kemudian diperluas cakupannya dengan mengunduh daftar kueri pencarian yang berkaitan dengan kueri pencarian dasar tersebut. 
Daftar kueri yang diunduh bukan hanya kueri pencarian yang berkaitan dengan kueri pencarian dasar, melainkan juga kueri yang berkaitan dengan kata kunci situs pencarian kerja. Proses ini menghasilkan daftar kueri pencarian lengkap yang berkaitan dengan kueri pencarian dasar dan dapat digunakan untuk memprediksi TPT. Kueri pencarian yang dihasilkan proses ini berjumlah 228 kueri pencarian.

\section{Daftar Kueri Pencarian Berkorelasi}

Kueri pencarian yang berkaitan dengan kueri pencarian dasar kemudian diseleksi dengan feature selection. Metode feature selection yang digunakan adalah filter method dengan metrik koefisien korelasi Pearson. Kueri pencarian yang memiliki koefisien korelasi Pearson lebih dari 0,7 kemudian dipilih untuk digunakan sebagai variabel untuk memprediksi TPT. Berikut merupakan daftar kueri pencarian yang memiliki koefisien korelasi Pearson dengan TPT lebih dari 0,7.

Tabel 1. Kueri pencarian yang berkorelasi kuat dengan TPT.

\begin{tabular}{lc}
\hline \multicolumn{1}{c}{ Kueri Pencarian } & Koefisien Korelasi \\
\hline lowongan pekerjaan & 0.93011 \\
lowongan kerja & 0.926642 \\
Pekerjaan & 0.80124 \\
Jobsdb & 0.770292 \\
karir.com & 0.785031 \\
lowongan kerja bandung & 0.874788 \\
lowongan kerja di bandung & 0.799057 \\
Info & 0.736606 \\
Job & 0.91366 \\
Karir & 0.713221 \\
Petromindo & 0.733969 \\
jobsdb.com & 0.719288 \\
\hline
\end{tabular}

\section{Seleksi Variabel}

Seleksi variabel dilakukan untuk mereduksi dimensi data yang digunakan dalam model dan mencegah overfitting. Selain itu, seleksi variabel juga dilakukan untuk menghapus variabel redundan dengan memilih variabel predictor yang paling optimal. Seleksi variabel pada tahap ini dilakukan menggunakan wrapper method yaitu LASSO. Berikut merupakan variabel yang diperoleh dari proses LASSO.

Tabel 2. Data indeks pencarian yang terseleksi dengan LASSO beserta nilai koefisiennya.

\begin{tabular}{ll}
\multicolumn{1}{c}{ Kueri Pencarian } & \multicolumn{1}{c}{ s0 } \\
\hline lowongan.pekerjaan & 0.031795 \\
lowongan.kerja & 0.011746 \\
Pekerjaan & $\cdot$ \\
Jobsdb & $\cdot$ \\
karir.com & $\cdot$ \\
lowongan.kerja.bandung & $\cdot$ \\
lowongan.kerja.di.bandung & $\cdot$ \\
Info & $\cdot$ \\
Job & 0.019183 \\
Karir & $\cdot$ \\
petromindo & $\cdot$ \\
jobsdb.com & $\cdot$ \\
\hline
\end{tabular}




\section{Hasil Optimisasi Antlion Optimization (ALO)}

Optimisasi menggunakan ALO dilakukan untuk mendapatkan parameter yang optimal untuk digunakan dalam pemodelan menggunakan SVR. Parameter yang dioptimisasi nilainya antara lain cost, epsilon, dan gamma untuk tiap-tiap model dengan kernel dan data split berbeda. Berikut merupakan tabel parameter hasil optimisasi dengan ALO untuk tiap-tiap model nowcasting.

Tabel 3. Hasil optimisasi SVR menggunakan ALO.

\begin{tabular}{|c|c|c|c|c|c|c|}
\hline \multirow{2}{*}{$\begin{array}{l}\text { Data } \\
\text { split }\end{array}$} & \multirow{2}{*}{ Kernel } & \multirow{2}{*}{$\begin{array}{c}\text { Jumlah } \\
\text { Iterasi }\end{array}$} & \multirow{2}{*}{$\begin{array}{l}\text { Waktu } \\
\text { (detik) }\end{array}$} & \multicolumn{3}{|c|}{ Parameter } \\
\hline & & & & Cost & Epsilon & Gamma \\
\hline $70 / 30$ & Radial & 10 & 2.530114 & 513.5 & 0.03125 & 0.501465 \\
\hline $70 / 30$ & Sigmoid & 21 & 4.729236 & 8.617521 & 0.03125 & 0.145754 \\
\hline $80 / 20$ & Radial & 10 & 2.449115 & 1024 & 0.03125 & 0.119506 \\
\hline $80 / 20$ & Sigmoid & 10 & 2.430128 & 2 & 0.03125 & 0.000977 \\
\hline $90 / 10$ & Radial & 7 & 1.712085 & 1 & 0.03125 & 0.000977 \\
\hline $90 / 10$ & Sigmoid & 11 & 2.737142 & 3 & 0.03125 & 0.000977 \\
\hline
\end{tabular}

Tabel 3 merupakan hasil optimisasi model nowcasting menggunakan ALO untuk tiap-tiap data split dan kernel. Berdasarkan tabel di atas, diketahui bahwa secara umum model dengan kernel sigmoid melakukan lebih banyak iterasi untuk mencapai parameter optimal dibandingkan model dengan kernel radial. Selain itu, jumlah iterasi juga berkurang secara rata-rata dengan penambahan jumlah data pada testing set. Model dengan pembagian training set dan testing set 90:10 memiliki rata-rata jumlah iterasi terkecil dibandingkan model dengan pembagian 80:20 dan 70:30. Waktu yang dibutuhkan untuk optimisasi juga berbanding lurus dengan jumlah iterasi yang dilakukan, sehingga model dengan iterasi yang lebih sedikit memerlukan waktu lebih singkat untuk mencapai parameter optimal.

\section{Pemodelan Nowcasting dengan SVR-ALO}

Parameter optimal yang telah diperoleh melalui optimisasi menggunakan ALO kemudian digunakan untuk membangun model nowcasting. Metrik evaluasi dari hasil peramalan model dengan optimisasi dan model yang menggunakan parameter default tanpa optimisasi digunakan untuk membandingkan hasil peramalan dari model-model tersebut. Berikut merupakan perbandingan hasil dari berbagai model nowcasting.

Tabel 4. MAE, RMSE, dan MAPE untuk hasil pemodelan menggunakan SVR dan SVR-ALO.

\begin{tabular}{|c|c|c|c|c|c|}
\hline Data Split & Kernel & Optimisasi & MAE & RMSE & MAPE \\
\hline \multirow{4}{*}{$70 / 30$} & \multirow{2}{*}{ Radial } & 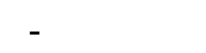 & 1.260069 & 1.353384 & 15.37286 \\
\hline & & ALO & 0.505302 & 0.585697 & 6.185372 \\
\hline & \multirow{2}{*}{ Sigmoid } & - & 1.088667 & 1.18269 & 13.29748 \\
\hline & & ALO & 0.205135 & 0.254027 & 2.462044 \\
\hline \multirow{4}{*}{$80 / 20$} & \multirow{2}{*}{ Radial } & - & 0.846366 & 0.942222 & 10.49829 \\
\hline & & ALO & 0.217603 & 0.294037 & 2.646348 \\
\hline & \multirow{2}{*}{ Sigmoid } & - & 0.523181 & 0.580696 & 6.450215 \\
\hline & & ALO & 0.371783 & 0.437421 & 4.627152 \\
\hline \multirow{4}{*}{$90 / 10$} & \multirow{2}{*}{ Radial } & - & 0.87763 & 0.89235 & 11.17668 \\
\hline & & ALO & 0.454899 & 0.487706 & 5.728541 \\
\hline & \multirow{2}{*}{ Sigmoid } & - & 1.618085 & 1.628117 & 20.25337 \\
\hline & & ALO & 0.227449 & 0.277627 & 2.882294 \\
\hline
\end{tabular}

Tabel 4 merupakan perbandingan metrik evaluasi hasil nowcasting dari tiap-tiap model. Berdasarkan tabel di atas, terlihat bahwa model dengan optimisasi menghasilkan peramalan yang 
lebih baik dibandingkan model yang parameternya tidak dioptimisasi. Hasil peramalan dengan parameter optimal pada model dengan kernel sigmoid dan data split 70:30 dan 90:10 cenderung lebih baik, tetapi model dengan kernel radial menghasilkan model yang lebih baik pada data split 80:20. Secara keseluruhan, model terbaik yang diperoleh dari proses pemodelan adalah model SVR-ALO dengan kernel sigmoid untuk data split antara training set dan testing set sebesar 70:30 dengan nilai MAE, RMSE, dan MAPE sebesar 0,2\%, 0,25\%, dan 2,46\%.

\section{KESIMPULAN}

Berdasarkan hasil penelitian dan pembahasannya yang telah diuraikan, peneliti mengambil beberapa kesimpulan bahwa terdapat 12 kueri pencarian dasar yang diperoleh melalui survei dan 12 situs pencarian kerja. Dari 24 kueri pencarian dasar tersebut, diperoleh 228 kueri pencarian terkait. Setelah dilakukan seleksi menggunakan feature selection terhadap kueri-kueri pencarian tersebut, diperoleh 3 kueri pencarian yang relevan dan dapat digunakan untuk nowcasting TPT Jawa Barat yaitu "lowongan kerja", "lowongan pekerjaan", dan "job".

Metode SVR-ALO dapat digunakan untuk nowcasting TPT. Metode tersebut menghasilkan out-of-sample yang baik, dengan model yang menggunakan $90 \%$ data sebagai data training memiliki hasil terbaik. Model SVR-ALO dengan data split 70:30 dan kernel sigmoid menghasilkan model dengan MAE sebesar 0,2 \%, RMSE sebesar 0,26\%, dan MAPE sebesar 2,46\%.

Penelitian ini menunjukkan bahwa data indeks pencarian Google Trends dapat digunakan sebagai sumber data alternatif untuk nowcasting TPT. Kombinasi data indeks pencarian Google Trends dengan metode machine learning seperti SVR yang dioptimisasi ALO menghasilkan model dengan peramalan out-of-sample yang baik.

\section{DAFTAR PUSTAKA}

Askitas, N., Zimmermann, K. F., Askitas, N., \& Zimmermann, K. F. (2009). Google Econometrics and Unemployment Forecasting. 4201.

Back, T. (1996). Evolutionary algorithms in theory and practice: evolution strategies, evolutionary programming, genetic algorithms. Oxford university press.

BPS. (2019). Survei Angkatan Kerja Nasional (SAKERNAS), 2019. https://sirusa.bps.go.id/sirusa/index.php/dasar/view?kd=5\&th=2019

Deng, Y. F., Jin, X., \& Zhong, Y. X. (2005). Ensemble SVR for prediction of time series. 2005 International Conference on Machine Learning and Cybernetics, ICMLC 2005, August, 3528-3534. https://doi.org/10.1109/icmlc.2005.1527553

Fondeur, Y., \& Karamé, F. (2013). Can Google data help predict French youth unemployment? 论. Economic Modelling, 30, 117-125. https://doi.org/10.1016/j.econmod.2012.07.017

Hoos, H. H., \& Stützle, T. (2004). Stochastic local search: Foundations and applications. Elsevier.

Mirjalili, S. (2015). The ant lion optimizer. Advances in Engineering Software, 83, 80-98. https://doi.org/10.1016/j.advengsoft.2015.01.010

Naccarato, A., Falorsi, S., Loriga, S., \& Pierini, A. (2017). Technological Forecasting \& Social Change Combining official and Google Trends data to forecast the Italian youth unemployment rate. Technological Forecasting \& Social Change, October, 1-9. https://doi.org/10.1016/j.techfore.2017.11.022

Richardson, A., Mulder, T. van F., \& Vehbi, T. (2018). Nowcasting New Zealand GDP Using Machine Learning Algorithms. CAMA Working Paper, 47.

Tam, S., \& Clarke, F. (2015). Big Data , Official Statistics and Some Initiatives by the Australian Bureau of Statistics. 436-448. https://doi.org/10.1111/insr.12105 
Virati, M. Q., Agustiyani, R., Pramana, S., \& Mariyah, S. (2019). Development of a Big Data Analysis System (Case Study: Unemployment Statistic). Asia-Pacific Economic Statistics Week 2019, June. 